\title{
Software Architecture System to Automate the Admission Process in the Higher Education Institutions
}

\author{
Dasharathraj K Shetty, B.H.S. Thimmappa, Namesh Malarout
}

\begin{abstract}
The admission process in the higher education system is one of the most tedious methods for parents and their wards. The common issues faced by them include confusion in the choice of the curriculum, equal care of individuals and the opportunities before them. The development of simple, scalable, and economical methods for admission process is the first step to realize their potential applications. Rational design and scalable approaches will enable an integrated system with multiple functionalities and broader applications. This paper proposes a software architecture model with several productivity features that uses the latest technologies to reduce inconveniences faced by applicants and their parents during the admission process. The application of this alternate model, adopting artificial intelligence-based technologies and its proper implementation can also minimize workforce and accelerate the admission process.
\end{abstract}

Keywords: Internet of Things (IoT); Near Field Communication (NFC); Radio-frequency Identification (RFID); Automatic Reality (VR); Internet Protocol version 6 (IPv6)

\section{INTRODUCTION}

The total number of degree-granting institutes in India are 700. This figure consists of 44 central universities (public), 306 state universities (public), 154 state universities (private), 129 deemed universities (private or public) and 67 institutes of national importance (public) excluding the 35,539 affiliated colleges (public or private) [(Ministry of Human Resource Development, Department of Higher Education, 2017)]. There has been a considerable increase in the enrolment of students in the higher education institutions and a vast number of specialties in different fields, increasing the complexity of the issues involved. Meritbased admission to a reputed public/private institutes in India is a very cumbersome, time-consuming and annoying process. The process starts with the sorting of applicants based on their declared rankings in the entrance examination. Applicants are informed about the documents, to bring for the admission before their arrival at the venue. Most of the institutes in the country provide counseling to the applicants and their parents during the admission process. This process helps the students from diverse backgrounds understand more about the importance of a

Revised Manuscript Received on October 15, 2019

Dasharathraj K Shetty, Department of Humanities and Management, Manipal Institute of Technology, Manipal Academy of Higher Education, Manipal-576104, India. (E : Mail : Raja.shetty@ manipal.edu)

B.H.S. Thimmappa, Department of Chemistry, Manipal Institute of Technology, Manipal Academy of Higher Education, Manipal, India , EMail: bhs.thims@manipal.edu

Namesh Malarout, Manipal Institute of Technology, Manipal Academy of Higher Education, Manipal, India Identification and Data Capture (AIDC); Biometrics; Virtual

particular branch of study, curriculum, infrastructure, laboratories, computer facilities, research and development activities, and placement possibilities to decide their preferred discipline. Students can also refer to brochures or handbooks provided by the institution for additional information. Even after the provision of counseling, applicants face the following multiple problems, and there is a need to make considerable changes in the conventional admission model to ensure speed, scale, and cost efficiency.

i. Choice of the curriculum: Applicants may get confused with the curriculum of the different branches which may hinder their ability to make the right decision. The technical terms in the brochure may be confusing to some applicants.

ii. Individual care: The massive crowd in the bustle of the conventional admission procedure makes it difficult for the faculty to provide equal care to every individual applicant and their parents. This aspect makes them confused with the options, and they might end up making the wrong choices, leading to psychosomatic disorders.

iii. Opportunities for applicants: There are a lot of options for an applicant which he/she might be unaware. One such instance may involve a situation where there is no vacancy in a branch, the applicant can fill up a waitlist form or can check if there is a vacancy in a specific department of the same university. The applicant can also apply for lateral entry in the second academic year after completing his first year in some other institute.

iv. Filling of multiple forms: A lot of paper is used up in the admission process for the applicant registration and to fill other necessary forms such as waitlist form, and feedback form.

v. Time consuming process: The admission process consumes about 3-6 hours. This time can be used in exploring the campus and the facilities provided.

These issues cannot be looked at in isolation, and the design of the technical module offers the business opportunities of the current global education market. The strategically planned system will allow the higher education system to operate the annual admission process quickly and service the customer better. There is a need to formulate and develop a more specific and scientific method to conduct the admission process smoothly. The specific objectives of this paper is to propose a Web-Based Software Architectural Model (WBSAM) to reduce the problems faced by applicants and their parents during the admission process of an institute, minimize the workforce required in the 
admission process, reduce the time consumed in the process, and resolve other specific challenges related to the admission process. The proposed model software architecture is composed by the internet of things (IoT), near field communication (NFC), radio-frequency identification (RFID), biometrics, and virtual reality (VR) concepts (Gubbi, Buyya, Marusic \& Palaniswami, 2013) (Madakam, Ramaswamy \& Tripathi, 2015) (Want, 2011) (Finkenzeller, 2003) (Jain, Bolle \& Pankanti, 2006) (Bricken \& Byrne, 1993)]. The overall model is more than the sum of its parts, and the transparent management system encompasses a multitude of specialized activities in the higher education institutions. The proposed architecture broadens perspectives, resulting in long-term or sustainable solutions in an era of interdisciplinary learning, embedding multiple disciplines in one stream across the universities. It helps the students to figure out their field of interest through informed choice and to avoid opting for an inappropriate subject under pressure.

\section{WEB-BASED SOFTWARE MODEL USE-CASE DIAGRAM}

The use-case diagram indicating the functionality of the admission process is shown in Figure 1. The software structure of the proposed model is depicted in Figure 2, while the description is incorporated in the Table 1 (Pradhan, B. Nanjappa, K. Nallasamy \& Esakimuthu, 2010).

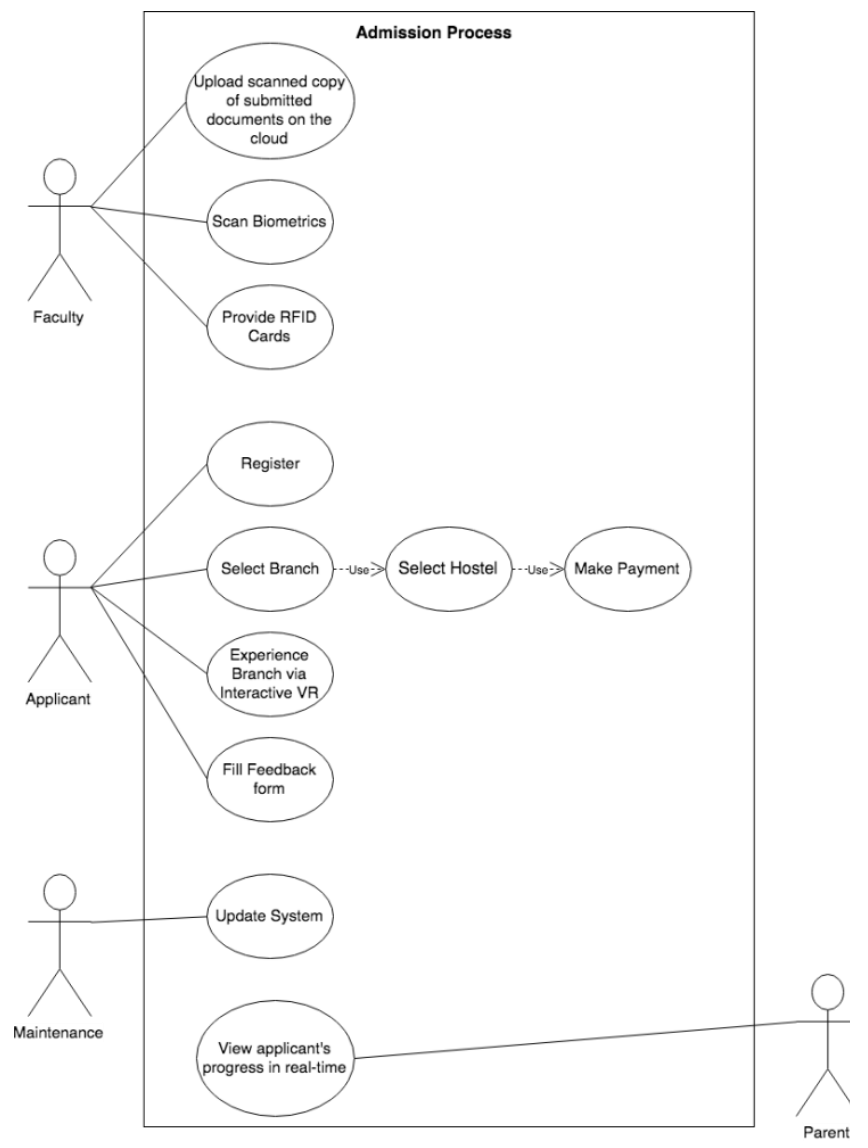

Figure 1. Use case diagram showing the various steps involved in the proposed admission process

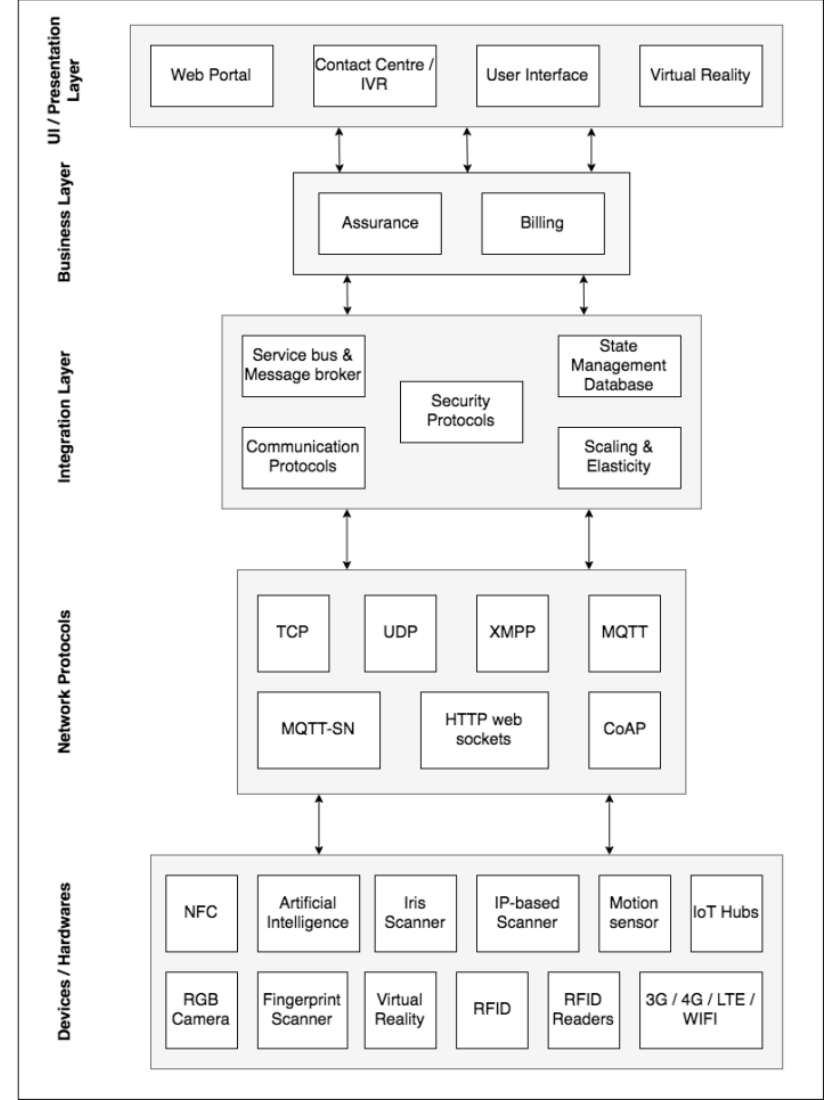

Figure 2. The software architecture of the proposed model incorporating special features

\begin{tabular}{|c|c|c|}
\hline Use case & Description & Actors \\
\hline $\begin{array}{l}\text { Upload } \\
\text { scanned copy } \\
\text { of the } \\
\text { documents }\end{array}$ & $\begin{array}{l}\text { - All the documents are scanned by the faculty member and uploaded to } \\
\text { the cloud-based database as shown in figure } 1 \text {. }\end{array}$ & \\
\hline $\begin{array}{l}\text { Scan bio } \\
\text { metrics }\end{array}$ & $\begin{array}{l}\text { - Faculty member scans applicant's bio metrics (fingerprints, iris scan and } \\
\text { face photo) and updates them to the system so that the applicants can } \\
\text { later use it to select their preferred branch. }\end{array}$ & \\
\hline $\begin{array}{l}\text { Provide RFID } \\
\text { cards }\end{array}$ & $\begin{array}{l}\text { - The applicants are provided with unique RFID cards by the faculty } \\
\text { members. }\end{array}$ & \\
\hline Register & $\begin{array}{l}\text { - Applicants use the NFC tags stuck on each desk to fill the registration } \\
\text { form. The NFC tags direct them to the page where they can fill the } \\
\text { registration forms. }\end{array}$ & \\
\hline Select branch & $\begin{array}{l}\text { - Applicants select their preferred branch on the touch-screen user } \\
\text { interface after viewing the previous year's selections on the user } \\
\text { interface. } \\
\text { - After selecting branch they select their preferred hostel from the } \\
\text { availability list on the user interface and then complete the transactions. }\end{array}$ & \\
\hline $\begin{array}{l}\text { Experience the } \\
\text { selected } \\
\text { branch in } \\
\text { holographic } \\
\text { view }\end{array}$ & $\begin{array}{l}\text { - Using this functionality, applicants can experience their selected branch } \\
\text { in holographic view in the next room after collecting the fee receipt. This } \\
\text { holographic view takes them through the practical labs, industrial visits, } \\
\text { classrooms, exams, workshops, etc. virtually which they will attend in } \\
\text { their tenure. } \\
\text { - The applicants can also experience their course virtually by soldering, etc. } \\
\text { in the holographic view }\end{array}$ & \\
\hline $\begin{array}{l}\text { Fill feedback } \\
\text { form }\end{array}$ & $\begin{array}{l}\text { - Applicants may fill the feedback form in the application at the end by } \\
\text { using the NFC tags placed at the exit reception. The NFC tags direct them } \\
\text { to the page where they can fill the feedback form. }\end{array}$ & \\
\hline Update system & $\begin{array}{l}\text { - The maintenance team updates the systems after each batch of } \\
\text { admissions are complete. }\end{array}$ & \\
\hline Make payment & - This option helps the parents can also make payments online. & \\
\hline $\begin{array}{c}\text { View } \\
\text { applicant's } \\
\text { progress online }\end{array}$ & $\begin{array}{l}\text { - Parents can view their ward's progress in the admission process from } \\
\text { anywhere in the world using their admission number. After every step, } \\
\text { the applicant's progress is updated online. }\end{array}$ & \\
\hline
\end{tabular}

Published By: 


\begin{tabular}{|c|c|c|}
\hline Use case & Description & Actors \\
\hline $\begin{array}{l}\text { Upload scanned } \\
\text { copy of submitted } \\
\text { documents on the } \\
\text { cloud }\end{array}$ & $\begin{array}{l}\text { All the documents are scanned by } \\
\text { the faculty member using IP- } \\
\text { based scanners which are } \\
\text { uploaded automatically to the } \\
\text { cloud-based database (as shown } \\
\text { in Figure 1). }\end{array}$ & Faculty \\
\hline Scan biometrics & $\begin{array}{l}\text { Faculty member scans the } \\
\text { applicant's biometrics } \\
\text { (fingerprint and iris scan) and } \\
\text { updates them to the system for } \\
\text { later use (Gopikrishnan \& } \\
\text { Santhanam, 2012). }\end{array}$ & Faculty \\
\hline Provide RFID cards & $\begin{array}{l}\text { The applicants are provided with } \\
\text { unique RFID cards which use } \\
\text { AIDC for identification and } \\
\text { detection. }\end{array}$ & Faculty \\
\hline Register & $\begin{array}{l}\text { Applicants use the NFC tags } \\
\text { stuck on the desks to fill the } \\
\text { registration form. These tags will } \\
\text { direct them to the web } \\
\text { registration form page. }\end{array}$ & Applicant \\
\hline Select branch & $\begin{array}{l}\text { Applicants select their preferred } \\
\text { branch on the touchscreen user } \\
\text { interface after viewing the } \\
\text { previous year's allotments and } \\
\text { then complete transactions. }\end{array}$ & Applicant \\
\hline $\begin{array}{l}\text { Experience branch } \\
\text { via interactive VR }\end{array}$ & $\begin{array}{l}\text { After collecting the fee receipt } \\
\text { and admission order, applicants } \\
\text { are directed to the next room } \\
\text { where they can experience their } \\
\text { selected branch in a } 360^{\circ} \\
\text { interactive VR. This experience } \\
\text { takes them through the practical } \\
\text { labs, industrial visits, classrooms, } \\
\text { exams, and workshops virtually. }\end{array}$ & Applicant \\
\hline Fill feedback form & $\begin{array}{l}\text { Applicants may fill the feedback } \\
\text { form using NFC tags placed at } \\
\text { the exit reception. These tags will } \\
\text { direct them to the feedback form } \\
\text { web page. }\end{array}$ & Applicant \\
\hline Update system & $\begin{array}{l}\text { The maintenance team updates } \\
\text { the systems after each batch of } \\
\text { admissions are complete. They } \\
\text { also check the security of the } \\
\text { system. }\end{array}$ & $\begin{array}{c}\text { Maintenanc } \\
\text { e }\end{array}$ \\
\hline $\begin{array}{l}\text { View applicant's } \\
\text { progress in real- } \\
\text { time }\end{array}$ & $\begin{array}{l}\text { Parents can view their ward's } \\
\text { progress from anywhere in the } \\
\text { world using their admission } \\
\text { number. After every step, the } \\
\text { applicant's progress is updated } \\
\text { online. }\end{array}$ & $\begin{array}{c}\text { Parent/Guar } \\
\text { dian }\end{array}$ \\
\hline
\end{tabular}

Table 1. Description of the use-case diagram

\section{SOFTWARE ARCHITECTURE OF THE PROPOSED MODEL}

The proposed IoT-based system has a five-layered architecture as shown in Figure 2.

1. Hardware system: The IoT is the communication between devices. These devices are interconnected and the internet as well. The near-field communication (NFC) tags indicate the users to form fill-up pages; the rule-based bots answers to queries; fingerprint scanner, an iris scanner, and red, green, blue (RGB) camera scan biometrics and face photo; the motion sensors, IP-based scanner for scanning documents, and interactive VR give an interactive display.
Internet protocol version 6 (IPv6) is used in IoT because of end-to-end encryption and more secure name resolution to avoid the imminent threat hackers pose to the internet, allows IoT products to be uniquely addressable without having to work around the traditional network address translation (NAT) and firewall issues. IPv6 also reduces problems in the transmission control protocol/internet protocol (TCP/IP) enabled IoT devices (Venkata Praneeth Reddy, Mohammed Imran Ali, Sandeep \& Ravi, 2012) (Nigam, Shukla \& Pratap Singh, 2016).

2. Network protocols: This layer of the architecture gives networking and addressing to the model. Extensible messaging and presence protocol (XMPP) (Extensible Markup Language, XML-based), message queuing telemetry transport (MQTT) (messaging protocol for small sensors), MQTT-SN (messaging protocol for sensor networks) are some of the network protocols used in the model (Pradhan, B. Nanjappa, K. Nallasamy \& Esakimuthu, 2010).

3. Integration layer: The integration layer provides the security model, authentication, and authorization. Service bus and message brokers ensure the communication of software applications. This layer adds resources and performance to the model.

4. Business layer: This layer gives the model, enrollment services, billing services, and assurance to the users.

5. Presentation layer: This layer is the face of the system and contains the components that implement and display the user interface and manages user interaction with the system. It could suggest what subject to opt in the waitlist and the applicants special requirements to the managers.

The notable productive features of the proposed system include

1. Document verification - The documents are scanned by an IP-based scanner and verified using image processing. For verification, the system searches the documents that are present in the various data repositories provided by the different agencies and then compares these certificates. This process reduces the time taken and workforce requirement in document verification.

2. Branch selection - The RFID cards provided to the applicants use automatic identification and data capture (AIDC). This system involves the methods of automatic object identification, data collection about them, and that data entry directly into computer systems. The unique RFID card can mark the presence of a candidate in a range of 30 meters. As soon as the applicant is in a 30 -meter radius from the user interface, it automatically detects the card and shows the previous five years' seat availability of that candidate's rank and details about the selected branch and placement information as they browse through it.

3. Online tracking - The data of the students are maintained in an electronic or paperless format, and parents can track their ward's progress on an online website from anywhere in the world. This online live status tracking 
model provides a comfortable and secure experience. After completion of every step, the applicant's progress will be updated in the cloud which can be viewed by their parents using their ward's admission number.

4. Interactive virtual reality - The applicants and parents can experience their branch and institution virtually beforehand using interactive virtual reality. It will be connected to the internet so that they can browse the entire campus in the hybrid view using advanced maps.

5. WBSAM System -The various subsystems are linked to each other and ease of doing yearly admission operations is an advantage for higher education institutions. After the first step, the technology used in that step relays the message to the next. This feature makes the process quick and easy. It can be used as a universal reporting mechanism that encompasses a multitude of specialized activities. This system helps educational institutions to function in a structure that is more transparent. It affects the comfort level of the learners and the ease of doing the business of educational investors.

\section{ACTIVITY DIAGRAM \& RESULTS}

The current generalized and the proposed system in the admission process are shown in Figure 3 and Figure 4 respectively.

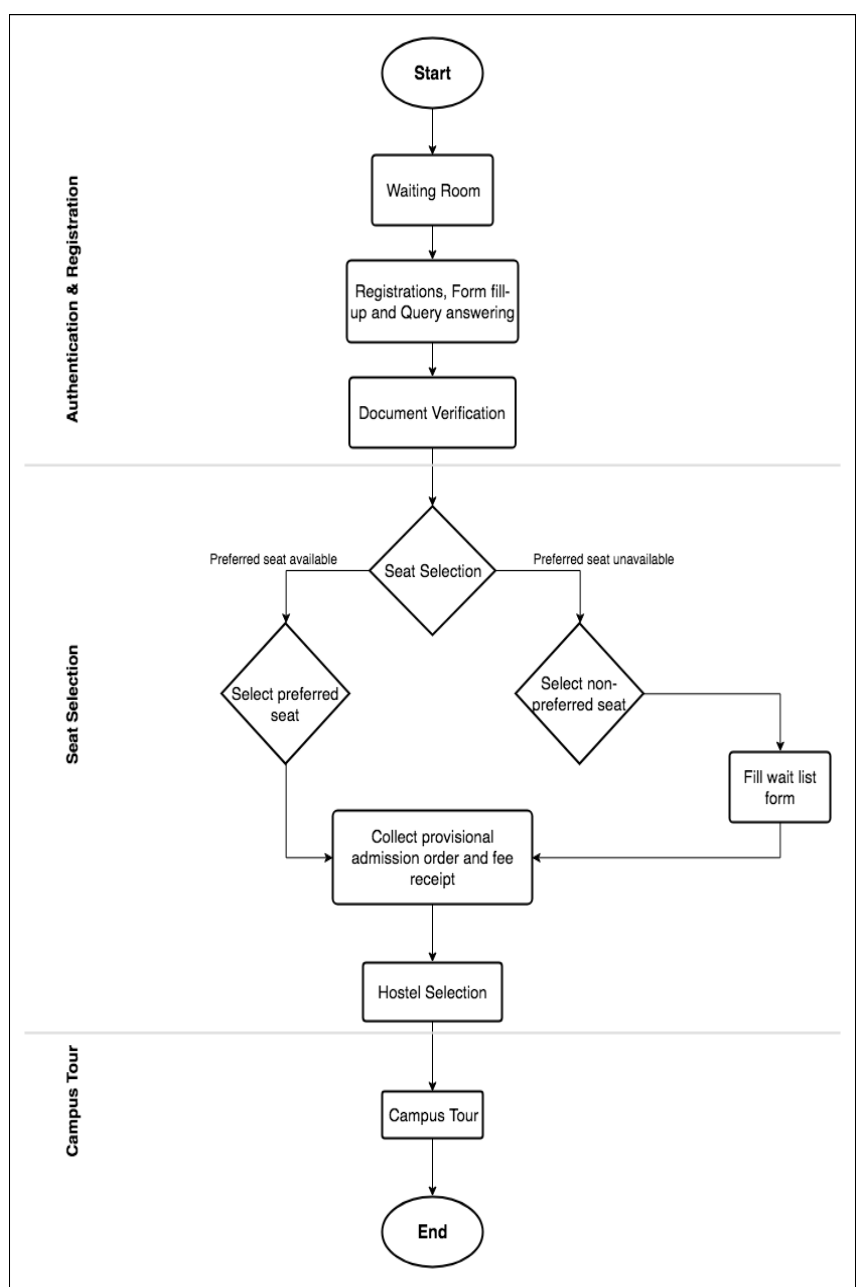

Figure 3. Current activity diagram indicating the stepby-step process in the admission process of institutions

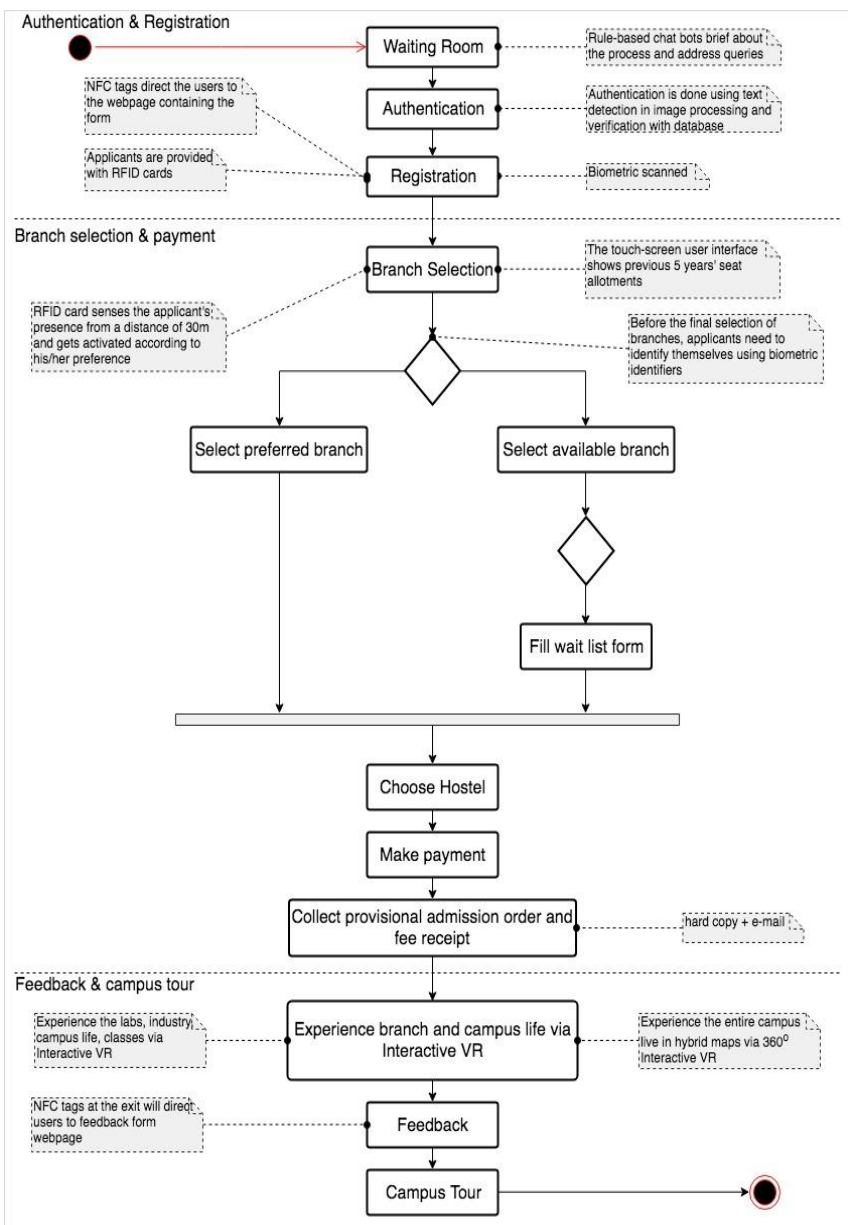

Figure 4. The proposed activity diagram in the model involving different steps in the overall process

1. The applicants will be directed to a waiting room where rule-based bots will brief them about the entire process and the documents required. The applicants and parents can clear their doubts by asking questions about the process or the institution to the rule-based bots (Augello, Pilato, Vassallo \& Gaglio, 2014). Documents will be scanned by the faculty members using IP-based scanners after verifying the required format of the documents and uploaded in the cloud-based database after authentication. For authentication, the system will search for the records that are present in various data repositories provided by different agencies and then compare it with the given documents using image processing and text detection. The applicants must use the NFC tags stuck on the desks to fill the admission form and register for the admission. The tag will direct the user to a website for filling up the form. These application forms will contain all the required details of the candidates with their interests and experiences so that the applicant can be informed about any event, workshop or project related to the mentioned interests beforehand. After authentication, each applicant will be provided with an RFID card which will act as the applicant's identity card and their biometrics (fingerprints, iris scan, and face photo) will be scanned by a faculty member. A unique medium range (30 meters) passive RFID card works using AIDC method. 
As soon as the applicant is in a 30-meter radius from the user interface, the RFID reader connected to it automatically detects the card. The user interface displays the previous five years' seat availability matrix for the candidate's rank, and details about the selected branch, placement information as the applicant browses through it.

2. After the applicant is satisfied with the information provided, the user interface will ask for the candidate's biometrics. The biometric identifiers connected to it will identify the candidates and direct them to the branch selection page. The applicant must select their preferred branch and hostel as per availability and then make the required payment. After the completion of the transaction, the candidates will receive a provisional admission order and fee receipt. The candidate can make the hard copy of the electronic version admission order of the attachment in the email if required.

3. We can then direct the applicants to a room where they can experience their curriculum and the campus through their senses using 360o VR headsets and interactive display (Wexelblat, 2015; Reitmayr \& Schmalstieg, 2001). The combined system will create an interactive VR display. So basically, a mechanical engineering applicant can use an engine lathe machine virtually, and an electrical engineering aspirant can try to solder a primary circuit virtually. This process is possible using motion sensors for movement, and hand gestures for working on the machine experience. This system interactive VR will be connected to the internet so that all the latest information about the institution will be provided to the applicant while browsing the campus through satellite in hybrid view. After the experience, applicants must return the RFID cards at the reception which can be re-used for the next batch of students and use the NFC tags at the reception desk to fill the feedback form. The NFC tag will instruct them to the website to fill the form. After they exit the building, they can approach the tour desk for a campus tour.

The proof of concept and the practical feasibility of the model in creating a self-sufficient, independent system where the students' benefit comes from the following multiple reasons. It is now possible to scan images/documents, identify the text and signatures, and authenticate these documents in a fraction of a minute due to the advancement of technology (Manwatkar \& Yadav, 2015; Liang, Doermann \& Li, 2005). The procedures involved in processing document images or images of text will require text detection, localization, extraction, geometrical normalization, enhancement/binarization, and recognition. The text on a simple scanned document which was stored as an image can be easily retrieved by the computer using this technology.

RFIDs are highly reliable, easy-to-use, have a moreextended range and very cheap to use. The combination of RFIDs and AIDC technology can be used for storing information and automatic identification of the products/people carrying the RFID tags ( $\mathrm{Su}, \mathrm{Chu}$, Prabhu \& Gadh, 2007). The person/object can be detected from a distance of 30 meters due to its long range. This process also opens doors for live tracking of these RFID tag carriers. The movement of each person/object can be traced in real-time along with the information assigned to them earlier.

Information on these RFID tags can be quickly erased and changed in a fraction of seconds (Turcu \& Turcu, 2012).

It can perform the task quickly and efficiently using a general purpose computer, administrative control programs, systems programs, and utility programs. It is a sophisticated software design that delivers a support system that strengthens the admission process in universities. It can be made available as specially packaged products with concrete concepts and values of management. The rough estimate of the software product package including necessary hardware and other accessories, operational and maintenance cost, and security services to customers is about 5800 USD. The higher education institutes can afford to purchase and use it for the benefit of the students. This model will enable us to proceed further to help improve the admission situation in most of the universities and may lead to automatic futuristic student life cycle management systems.

\section{CONCLUSIONS AND PROSPECTS}

In this account, we have presented our strategies to achieve a smooth admission process. In an attempt to blend technology with the admission process, we have used RFID, VR and IoT solutions so that more people may benefit and build on it. The proposed software architectural model, when implemented, will help in reducing the confusion in the choice of the particular branch of study, and provide equal attention to all of the participants in the process and will reduce inconveniences faced by applicants and their parents during the admission process. It can minimize workforce and accelerate the admission process. It will also help them to get the virtual feel of the branch and the institute before spending their most precious years on the campus. This system could play a supplementary role in the overall education sector, but we can concentrate our thoughts and actions on developing the professional competitiveness instead of spending time on routine admission considerations. It is clear that the projected model is expected to help in creating a favorable education ecosystem accelerating development projects and in the student welfare to a large extent. This practical admission model can be instrumental in the fast-changing world, especially for institutions that have decided to raise the bar and be a role model. Extensions of this model may lead to the design of new functional systems and surpass the capabilities of conventional protocols.

This technical module involving transforming engineering ideas into an outstanding admission experience in the higher education system is expected to impact the physical, psychological and social lives of young learners. The effectiveness of the technologies used in this concept will be known only after the implementation of the proposed scheme. Hence, a study may be carried out on the effectiveness of the technologies used, and replacements can be made accordingly to enhance the quality of the service to make it more affordable, scalable, sustainable as well as rapid, and universal. 
Also, it can keep track of overall enrolment of students, and if extended, it can play a crucial role in managing yearly fees, miscellaneous payments to the institute, students' assessment-related data, and other educational core activities involving various parameters at maximum speed to achieve better delivery management. Excellence in execution makes the journey inspired from the perspective of growing small to mid-size educational organizations when the system of the alternative admission process is in place across the country. This architectural model can be replicated elsewhere with minor changes in some parameters that are used in practice in various parts of the planet.

\section{REFERENCES}

1. Augello, A., Pilato, G., Vassallo, G., \& Gaglio, S. (2014). Chatbots as Interface to Ontologies. Advances in Intelligent Systems And Computing, 285-299. doi: 10.1007/978-3-319-03992-3_20.

2. Bricken, M., \& Byrne, C. (1993). Summer Students in Virtual Reality. Virtual Reality, 199-217. doi: 10.1016/b978-0-12-745045-2.50019-2.

3. Finkenzeller, K. (2003). RFID Handbook (3rd ed.). Newark: Wiley.

4. Gopikrishnan, M., \& Santhanam, T. (2012). Improved Biometric Recognition and Identification of Human Iris Patterns Using Neural Networks. Journal of Algorithms \& Computational Technology, 6, 411-420. doi: 10.1260/1748-3018.6.3.411.

5. Government of India. (2017). All India Survey on Higher Education 2016-17, 1-45. New Delhi, Ministry of Human Resource Development.

6. Gubbi, J., Buyya, R., Marusic, S., \& Palaniswami, M. (2013). Internet of Things (IoT): A vision, architectural elements, and future directions. Future Generation Computer Systems, 29(7), 1645-1660. doi: 10.1016/j.future.2013.01.010.

7. Jain, A., Bolle, R., \& Pankanti, S. (2006). Biometrics. New York: Springer.

8. Madakam, S., Ramaswamy, R., \& Tripathi, S. (2015). Internet of Things (IoT): A Literature Nigam, S., Shukla, R., \& Pratap Singh, A. (2016). Introduction and need of IPv6. International Journal of Innovative Computer Science \& Engineering, 3(2), 35-37.

9. Review. Journal of Computer and Communications, 03(05), 164-173. doi: 10.4236/jcc.2015.35021.

10. Pradhan, A., B. Nanjappa, S., K. Nallasamy, S., \& Esakimuthu, V. (2010). Raising Enterprise Applications: A Software Engineering Perspective (1st edn.). Wiley India Pvt. Ltd.

11. Reddy, V. P., P., Mohammed Imran Ali, K., Sandeep, B., \& Ravi, T. (2012). Importance and Benefits of IPV6 over IPV4: A Study. International Journal of Scientific and Research Publications, 2(12), 517-518.

12. Reitmayr, G., \& Schmalstieg, D. (2001). An open software architecture for virtual reality interaction. In ACM symposium on virtual reality software and technology (pp. 47-54). Banff: ACM. Retrieved from https://dl.acm.org/citation.cfm?id=505018

13. Liang, J., Doermann, D., \& Li, H. (2005). Camerabased analysis of text and documents: a survey. International Journal of Document Analysis and Recognition (IJDAR), 7(2-3), 84-104. doi: 10.1007/s10032-004-0138-z

14. Manwatkar, P., \& Yadav, S. (2015). Text recognition from images. 2015 International Conference on Innovations in Information, Embedded and
Communication Systems (ICIIECS). doi: 10.1109/iciiecs.2015.7193210

15. Su, X., Chu, C., Prabhu, B., \& Gadh, R. (2007). On The Creation of Automatic Identification and Data Capture Infrastructure via RFID. The Internet of Things: From RFID to the Next-Generation Pervasive Networked Systems, 1-19. Retrieved from https://pdfs.semanticscholar.org/4551/8902ca4e297e3 aa96310c353caf2e5b5403e.pdf.

16. Turcu, C., \& Turcu, C. (2012). RFID-based Solutions for Smarter Healthcare. International Workshop Fostering Innovation in Healthcare Services, 1-4.

17. Want, R. (2011). Near Field Communication. IEEE Pervasive Computing, 10(3), 4-7. doi: 10.1109/mprv.2011.55.

18. Wexelblat, A. (2015). Virtual Reality. Saint Louis: Elsevier Science. 